\title{
Sesame as functional food
}

\begin{abstract}
Sesame (Sesamum indicum L.) seeds have been consumed and utilized from long to season salads, foods, sprinkle, in confectionaries, baking for medicinal and various other purposes. Extraordinary power boosters' sesame super-food is rich in most of the nutrients. These small powerful packages contains immense amount of wellbeing. Particularly the black colored sesame seeds that is rich in reserves of calcium zinc etc. Genuinely, sesame seeds are reasonable units of fiber and protein alongside other essential minerals like calcium, manganese and copper. It has numerous benefits specifically for its role in curing liver issues.
\end{abstract}

Volume 12 Issue 3 - 202 I

\author{
Hina Saleem,' Hafeez Ahmad Sadaqat,' \\ Humera Razzaq,' Qasim Farooq ${ }^{2}$ \\ 'Department of Plant Breeding and Genetics, University of \\ Agriculture, Pakistan \\ ${ }^{2}$ Department of Botany, University of Agriculture, Pakistan
}

Correspondence: Hina Saleem, Department of Plant Breeding and Genetics, University of Agriculture, Faisalabad 38040, Pakistan, Tel 03216374764, Email hinah3099@gmail.com

Received: May 18, 2021 | Published: June 04, 2021

\section{Introduction}

One of the most ancient and powerful seeds known by now are sesame seeds. Their history is as old as most probably the ancient civilizations found on earth. Moreover, sesame plants are the most commonly used commodity known to mankind. This plant species is developed basically for their oil and seed purposes instead of for their vegetable or other floral pasts like in the cases of other crops.

Exceptionally esteemed in Mediterranean, African and eastern societies, sesame (Sesamum indicum L.) seeds have been consumed and utilized from a longer period of time to season the salads, foods, sprinkle, in confectionaries, baking for medicinal and various other purposes. Sesame seed oil is the best oil known so far and has the greatest oil quality and flaunts a rich mesmerizing nutty flavor, also known as liquid gold which is the reason it along with the "tahini" (i.e. specially processed in African and Arabic culture) and the seeds are normal ingredient used in foods across the world. The seeds contain up to $50 \%$ to 60 percent of oil and contain the most important ingredient from the lignan family: a) sesamin and b) sesamolin. These phenolic compounds are more refined during oil process and holds immense nutritional and medicinal importance.

Sesame oil is extracted from its seeds the most common used specie for general cultivation purposes is Sesamum indicum L. which is commonly used for medicinal and cooking purposes in most of the Asian nations. Recent analysis has shown some antioxidative properties of sesame oil. ${ }^{1}$ It prevents lipid peroxidation and reduces levels of hydroxyl progressive and nitrites through raising activities of catalyst agent that prevents cancer. ${ }^{2}$ Besides, it enhances lipid aggregation in adipocytes through concealing of lipogenesis, and lifts lipolysis. ${ }^{2}$ It also shows preventive effects for advancement of atherosclerosis ${ }^{4}$ and hypertension. ${ }^{5}$ These medical advantages are ascribed to the cell reinforcement and calming exercises ${ }^{6}$ the lignans (sesamol in sesamin and sesamol) and tocopherols. Lignans in sesame oil have been generally thought with respect to their preventive concept of cancer causing agents, ${ }^{7}$ antihypertensive,${ }^{8,9}$ and antihyperlipidemic impacts. ${ }^{10}$ In the past analysis, the proportions of sesamin, sesamolin, and tocopherols in sesame oil were found to be $6.02,3.84$, and $1.45 \mathrm{~g} /$ $\mathrm{kg}$, which is higher than in soybean oil. Besides, polyunsaturated unsaturated fats that have cell antioxidation movement are high in sesame oil. Oleic acid content (38.84\%), Arachidonic acid content $(0.9 \%)$ and Linoleic acid content $(46.26 \%)$ are present in immense amount in sesame oil. ${ }^{11}$

\section{Health related benefits}

\section{Sesame and liver}

The lignans present in sesame seeds help liver function with the only few enzymes that can separate unsaturated fats productively. Sesame seeds are stacked with lignans that work with cell reinforcement action in our body and help in better retention of fatdissolvable supplements derived from other food. ${ }^{12}$

Sesame seeds are perhaps the most impressive healing food product that prevails in the world. For millennia they have been utilized by conventional people groups for food and medication. Chinese medication proposes this antiquated food may help assuage the pestilence of liver harm from current medications.

Hepatotoxicity is liver harm brought about by synthetic substances. It's a critical issue identified with drug use since the liver's responsibility is to clear synthetic substances from the body. That makes the liver especially powerless to injury from drug use. Even when use in correct doses, hundreds of the dugs contributes to the toxicity of liver. This is one of the many reason that why drugs are removed from the market. A publication in the Journal of the Chinese Medical Association states that at present "a hepatoprotectant is the dire need of time." It additionally recommends that sesame seeds and its oil likely could be used as protectant.

Sesamin additionally shields against damage to the liver caused from liquor and drug use. Several studies based on animal from Taiwan and Japan shows that sesame oil decreases oxidative stress in the liver. Some other studies indicated that sesame oil can also tackle the harmful effects of the drug acetaminophen on the liver. Each year this drug causes more than four hundred and fifty deaths from the failure of liver. Sesamin in seame oil combat the damage by maintaining level of glutathione i.e. a potent antiodxidant. As this drug acetaminophen tends to reduce liver's storage for glutathione. Sesamin also tends to reduce free radicals and inhibits the oxidation of fats.

Different investigations show sesame oil can battle the hurtful impacts of acetaminophen on the liver. Every year acetaminophen causes in excess of 450 passings from liver disappointment. Sesamin helps battle that harm by keeping up intracellular degrees of glutathione, powerful cell reinforcement. Acetaminophen is known to decrease the liver's store of glutathione. Sesamin likewise lessens the degrees of free extremists and restrains oxidation of fats. 
Not only does sesamin fight liver damage but also aids with liver related issues, particularly from the compounds containing acetaminophen, like Tylenol, it truly gives better assistance with distress. Earlier Green Med Info uncovered that eating 40grams of sesame seeds (around two tablespoons of tahini) was superior to Tylenol in diminishing misery in that encountering knee joint irritation. Placebo-controlled, blind, parallel group of study was carried out among 48 Japanese subjects found that oral doses of sesamin are safe and adequate in terms of improving.

In most of the Asian cuisines sesame seed is quiet popular it is almost a common commodity in every kitchen along with its oil. The seeds are a valuable part of the plant that is mostly harvested from the plant species called "Sesamum indicum" that quiet possible have its roots back in Africa. Today it is produced in most part of the Asian countries generally in Pakistan, India and China. In the tropical the Caribbean and southern U.S., the seeds of sesame are consistently known by their common popular African name, called as "benne".

The seeds of sesame are found in range of colors like skin, creamy, yellow, black, red and brown. They fill in units which tend to burst open when prepared. This should be the reason of the magic articulation "open sesame" in the forty thieves' in the "Arabian Nights". Sesame seeds pack a wide bunch of other clinical benefits. They are a fair wellspring of magnesium,B1 (thiamine), copper, calcium, zinc, manganese and phosphorous they can be eaten whole, ground into "tahini", "glue" or dealt with into oil. Its oil contains polyunsaturated fats and is a wellspring of omega-3 unsaturated fats.

Its oil has a striking flavor and works out decidedly for garlic and ginger in fields and blends fries. Because of its high functional nutrients and medicinal properties content, most sesame oil can be used for cooking. In case you will cook with sesame oil, look for rough sesame oil which isn't misleadingly pre-arranged.

\section{Rich in nutrients}

Extraordinary power booster's sesame super-food is rich in most of the nutrients. These small powerful packages contains immense amount of wellbeing. Particularly the black colored sesame seeds that is rich in reserves of calcium zinc etc. Sesame seeds are essential units of fiber and protein alongside other important minerals like calcium, manganese and copper (Figures $1 \& 2$ ).
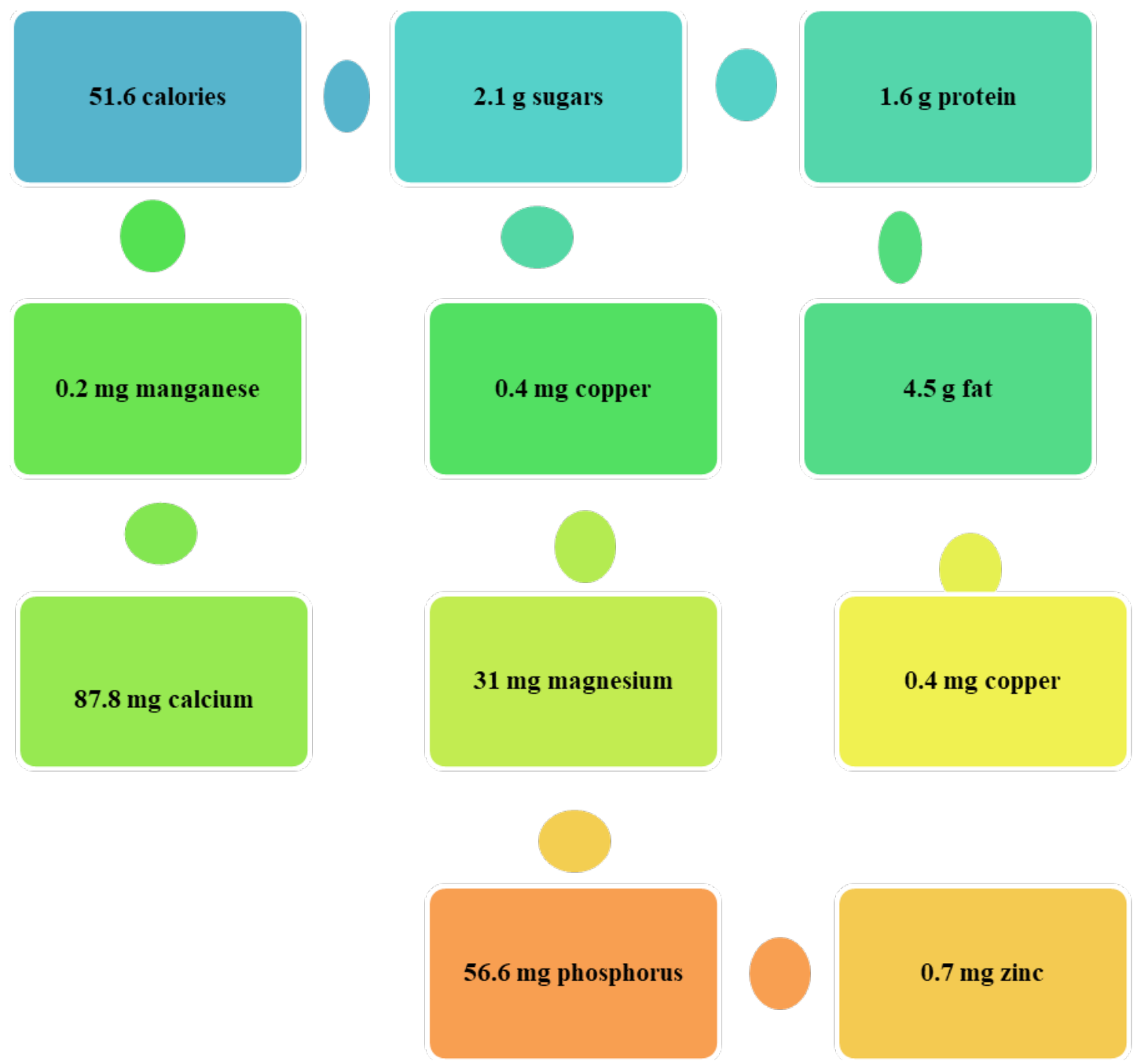

Figure I Notwithstanding the supplements recorded above, sesame seeds additionally contain a limited quantity of selenium, potassium, folate, niacin and riboflavin.

potassium, folate, niacin and riboflavin. 


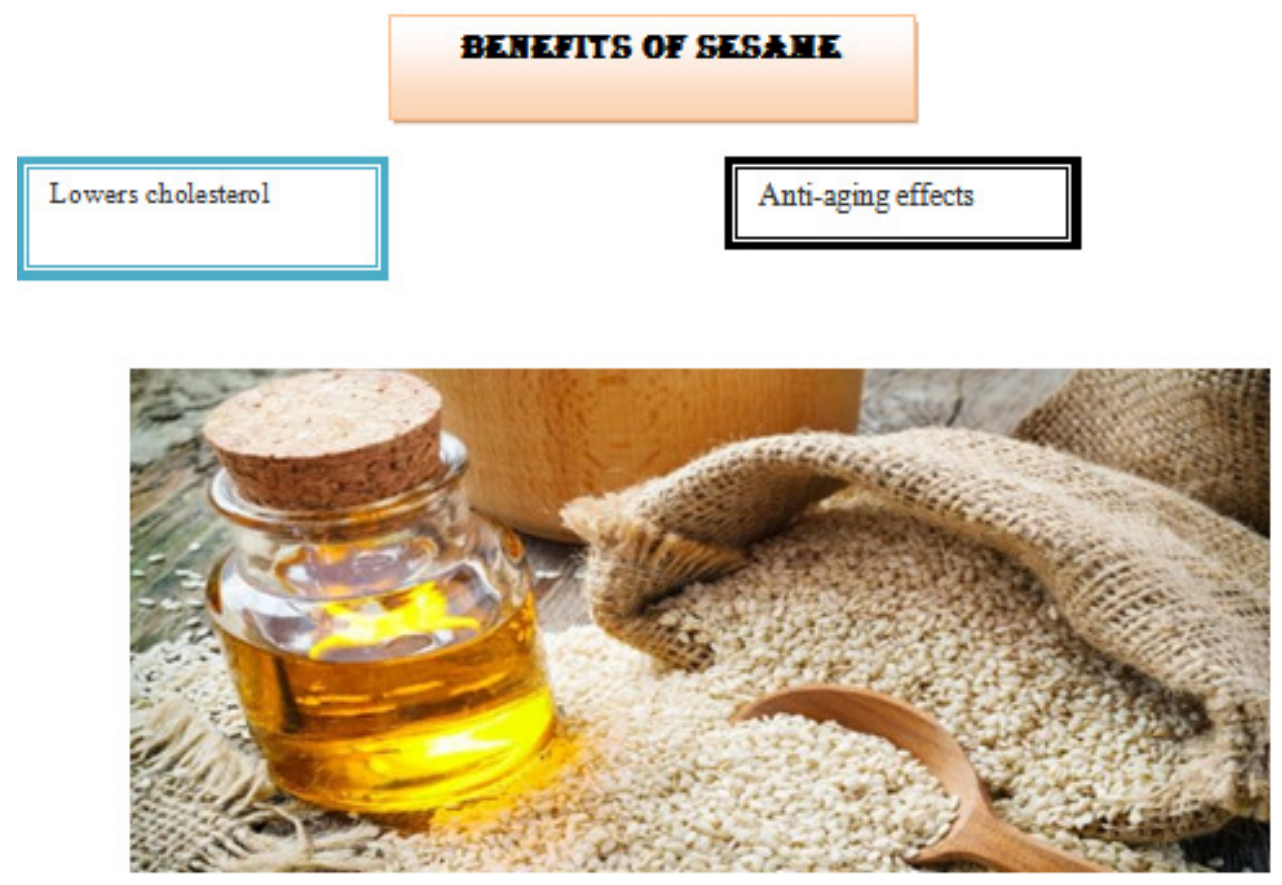

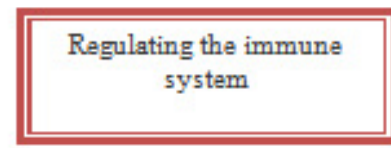

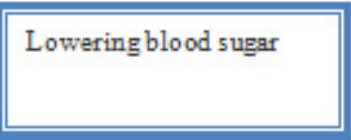

Figure 2 Benefit s of sesame.

The content of iron present in the sesame seeds can help with deficiency of iron that is associated with sickle cell anemia and lifts low energy levels. Although the deficiency of copper is not a serious ailment, still this can be overcome by using sesame seeds as sesame seeds have ample amount of the copper needed in consistently to keep up metabolic prosperity and nerve health.

\section{Dental health}

The sesame seed oil helps in eliminating dental plaque and lifts oral wellbeing.

\section{Aids in digestion}

The black colored sesame seeds are nutritionally very important these contains immense amount of fibers that aids in digestion it helps to lubricate the intestines and stomach. Sesame seed oil can grease up your assimilation lots, whereas the fiber present in it aids smoother strong defecation.

\section{Lifts skin health}

The sesame seed oil can do wonders considerations for the skin. The phenolics compound in it helps the skin with stays graceful, maintains the youth, delicate, soft and supple. They are rich in antiaging properties that are basic in taking care of skin inflammation redness, wounds and other facial skin issues from within.

\section{Antithrombotic}

effects

Antioxidant power

\section{Reduces the risk of liver cancer}

As shown by Dr. Ronald A DePhino ${ }^{13}$ Principal Investigator, M.D. Anderson Cancer Center, Houston, the essential phenolic compound "sesamin" found in the seeds of sesame profoundly aids to improve the liver damage and helps to promote liver functions. Similarly, these magical seeds are rich in fiber content that strengthen the cell wall elasticity and functioning and also contains phytosterol (phytochemicals), which can aids you well in the betterment of colon infection.

\section{Relief from constipation and indigestion}

The light colored sesame seeds most appropriately the skin ones helps in digestion and relieves many stomach related issues. It aids in immensely decreasing the fat substances which also aids in weight loss as well. The oil presents in these seeds help to lubricate the intestines and ducts in digestive system while the fiber in the seeds helps to give you smoother defecation. This seed furthermore aid in removing the worms present in the intestinal plot and facilitates the absorption association." Grinding the seeds or sprinkling them on food can help make the seeds more consumable.

\section{Battles the growth of cancer cells}

Comparable as linseed or flaxseeds it is found that sesame seeds also contain ample amount of lignin and its related compounds. These 
particular compounds are made by the colon micro flora that is present inside the colon and have been seemed to have amazing effects on suppressing the growth of several specific types of cancer.

"Department of Nutritional Sciences" at the "University of Toronto" carried out the study in 2005 investigated the impacts of blend of flaxseed and sesame seeds. About $25 \mathrm{mg}$ of this blend was given to the postmenopausal women with the 2 days interval over a period of four weeks. The results concluded via the urine test suggested that those women who used blend of flaxseed and sesame seed have developed an increase in the mammalian lignans, suggesting women who receive this lignin via flaxseeds and sesame blend led to the significance conversion of these compounds into more useful form by colon flora that helped in against the growth of cancer cells. ${ }^{14}$

Moreover a similar analysis was published in 2012 via a new report that was issued in the "Journal of Nutrition" also concluded that the dietary lignans may probably act as a natural cancer preventive treatment that reduces the breast cancer risk by the modification of the tumor characteristics. This study concluded that lignin intake resulted in lower estrogen receptor i.e. negative breast cancer. The study used 683 females with breast cancer and 611 healthy females without breast cancer for evaluation. And hence it was found that higher intake of lignans led's to lower chances of cancer development. ${ }^{15}$

\section{Lift fat-burning}

A few investigations recommend that specific mixtures found in sesame seeds could help support fat-consuming and holds the waistline under control. Indeed, a 2012 creature concentrate out of Maryland really tracked down that giving rodents a powder improved with lignans diminished both body weight and fat gathering. ${ }^{16}$

\section{Utilizations in traditional medicine}

Sesame seeds are consistently used in various kinds of far reaching medicine for a long time, due to their therapeutic and prosperity propelling properties. According to the diet plan of Ayurvedic sesame seeds have been utilized on an empty stomach to go without for longer hours, it helps to fill the appetite, immensely increases the level of energy, boosts the metabolism and strengthens the immune system. Sesame oil is an excellent source for curing many common flu and other related infections, in fact it is the most powerful medicinal plant that is used to cure diabetes too. Using few drops of its oil for sniffing and in nasal cavity relaxes the nasal infections and dryness moreover helps to maintains dental health.

According to "Traditional Chinese Medicine", black sesame seeds helps tonify the blood, improves kidney and liver health. They are also used to treat backaches, constipation, dizziness and weakness. Take one look at the sesame seeds food profile, and it's not hard to see any motivation behind why these minute yet unbelievable these tiny super food are magnificent for the prosperity. Every single serving of sesame seed sustenance nourishment in a good proportion and causes nutritional enhancements, including high proportions of copper, manganese and protein.

\section{Acknowledgments}

None.

\section{Conflicts of interest}

All authors declared there are no conflicts of interest.

\section{Funding}

None.

\section{References}

1. Anilakumar KR, Pal A, Khanum F, et al. Nutritional, medicinal and industrial uses of sesame (Sesamumindicum L.) seedsan overview. Agric ConspecSci. 2010;75:159-168.

2. Baluchnejadmojarad T, Roghani M, JalaliNadoushan MR, et al. The sesame lignansesamin attenuates vascular dysfunction in streptozotocin diabetic rats: involvement of nitric oxide and oxidative stress. Eur $J$ Pharmacol. 2013;698(1-3):316-321.

3. Bhaskaran S, Santanam N, Penumetcha M, et al. Inhibition of atherosclerosis in low-density lipoprotein receptor negative mice by sesame oil. J Med Food. 2006;9(4):487-490.

4. Che Man YB, Rohman A, Mansor TST. Differentiation of lard from other edible fats and oils by means of fourier transform infrared spectroscopy and chemometrics. J Am Oil Chem Soc. 2011;88:187-192.

5. Choi BH, Kang KS, Kwak MK. Effect of redox modulating NRF2 activators on chronic kidney disease. Molecules. 2014;19(8):1272712759.

6. Deji N, Kume S, Araki S, et al. Structural and functional changes in the kidneys of high-fat diet-induced obese mice. Am J Physiol Renal Physiol. 2009;296(1):F118-F126.

7. Folch J, Lees M, Sloane Stanley GH. A simple method for the isolation and purification of total lipides from animal tissues. $J$ Biol Chem. 1957;226(1):497-509

8. Geetha T, Rohit B, Pal KI. Sesamol: an efficient antioxidant with potential therapeutic benefits. Med Chem. 2009;5(4):367-371.

9. Hamada N, Tanaka A, Fujita Y, et al. Involvement of heme oxygenase-1 induction via Nrf2/ARE activation in protection against $\mathrm{H} 2 \mathrm{O} 2$-induced PC12 cell death by a metabolite of sesamin contained in sesame seeds. Bioorg Med Chem. 2011;19(6):1959-1965.

10. Harikumar KB, Sung B, Tharakan ST, et al. Sesamin manifests chemopreventive effects through the suppression of NF- $\kappa$ B-regulated cell survival, proliferation, invasion, and angiogenic gene products. $\mathrm{Mol}$ Cancer Res. 2010;8(5):1541-7786.

11. Hsu DZ, Chiang PJ, Chien SP, et al. Parenteral sesame oil attenuates oxidative stress after endotoxin intoxication in rats. Toxicology. 2004;196(1-20:147-153.

12. Ide $\mathrm{T}$, Hong DD, Ranasinghe $\mathrm{P}$, et al. Interaction of dietary fat types and sesamin on hepatic fatty acid oxidation in rats. Biochim Biophys Acta. 2004;1682(1-3):80-91.

13. Farazi PA, DePinho RA. The genetic and environmental basis of hepatocellular carcinoma. Discov Med. 2006;6(35):182-186.

14. Coulman KD, Liu Z, Hum WQ, et al. Whole sesame seed is as rich a source of mammalian lignan precursors as whole flaxseed. Nutr Cancer. 2005;52(2):156-65.

15. McCann SE, Hootman KC, Weaver AM, et al. Dietary intakes of total and specific lignans are associated with clinical breast tumor characteristics. $J$ Nutr. 2012;142(1):91-98.

16. Jung K, Hong SH, Kim M, et al. Antiatherogenic effects of Korean cabbage kimchi with added short arm octopus. Food Sci Biotechnol. $2015 ; 24: 249-255$.

17. Kanimozhi P, Prasad NR. Antioxidant potential of sesamol and its role on radiation-induced DNA damage in whole-body irradiated Swiss albino mice. Environ Toxicol Pharmacol. 2009;28:192-197. 